why the influence of the registrar training should be a prime concern of those wishing to improve higher training. The problems of registrar training, and particularly the effect that the MRCPsych exam has on this, have been discussed elsewhere.

\title{
The AUTP and the College
}

An urgent question in this context is the standard of the Approval Exercise carried out by the Royal College-are the standards high enough for the training schemes to produce good potential senior registrars? There is a danger with this scheme-and the College is, out of necessity, preoccupied with this problem - that raising the very low standards of the poorest hospitals is the most urgent aspect. But what about further raising the standards of the best training? This is criticized as an 'elitist' point of view, but would be my personal view of the role of the universities. Aubrey Lewis would have perhaps been more radical and suggested that, in order to maintain a satisfactory standard of approval of posts, this should not be in the hands of the same body that organizes the examination.'

Peter Brook ${ }^{2}$ wrote in 1974 that the then new Joint Committee on Higher Psychiatric Training 'should formulate guidelines for programmes of training and then approve them as speedily as possible' (my italics). One sometimes senses that speed is more important than standards, but the Approval exercise at both levels can only bring about change and improvement if it is done slowly. Professor Shepherd told the 1969 conference on postgraduate training' ${ }^{13}$ that 'an improvement of teaching facilities in every psychiatric hospital ... is desirable but can only be achieved by ensuring that regional psychiatric hospitals employ senior staff who have received a thorough postgraduate training and are willing and able to participate in teaching programmes. At present there are too few people who can be

\section{Reports and Pamphlets}

\section{'Tied Together With String' by Diana Priestley 'Home Sweet Nothing' \\ Both published by the National Schizophrenia Fellowship}

In the rather complex world of voluntary organizations and pressure groups (often hiding under dramatic titles), the National Schizophrenia Fellowship has been marked out by its eminently practical aims and by its firm alliance with professional workers. This does not stop it, though, from being highly critical where services are poor. It has also sought to provide some protection and comfort for the families of schizophrenics from the odium heaped on them by environmental doctrines of aetiology, such as those of Laing and regarded as satisfying these criteria'. The role of the College and the Association of University Teachers of Psychiatry must surely be to ensure that the next generation of consultant staff do satisfy these criteria.

\section{REFERENCES}

' ASPY, D. N., 'Teaching skills'. Journal of Medical Education. $1978,53,871$.

${ }^{2}$ Brook, P., 'The postgraduate education and training of consultant psychiatrists'. Brit. J. Psych. 1974, 124, 109-24.

${ }^{3}$ Brook, P., 'Objectives and training in psychiatry'. Brit. J. Psych. 1975, 126, 550-55.

4 Brook, P., Psychiatrists in Training. British Journal of Psychiatry Special Publication No 7, 1973.

' Clare, A. W., 'Training of psychiatrists'. Lancet. 1972, ii 753-6.

- Crow, T. J. 'The scientific status of electro-convulsive therapy'. Pssychological Medicine. 1979, 9, 401-8.

' Kardener, S. H., Fuller, M., Mensh, I. N. and Forgy, E. W., 'The trainees' viewpoint of psychiatric residency'. American Journal of Psychiatry. 1970, 126, 1132-8.

'LEWIS, A. J., 'The education of psychiatrists'. Lancet. 1947, ii, 79 83.

'Mezey, A., 'An open letter to the President'. Bulletin of the Royal College of Psychiatrists. 1978, August, 147-9.

${ }^{10}$ NorTH, A. F. Jr., 'Evaluation of a paediatric House Officer programme by alumni'. J. Med. Education. 1965, 10, 1145-53.

"POND, D. A., 'Health service provision for medical education in England and Wales: Can standards by maintained?' Bulletin of the Royal College of Psychiatrists. 1979, September, 130-1.

12 Royal College of Psychiatrusts. 'Approval visits: Guidelines on criteria and facilities for training'. Bulletin, 1978, September, 158-9.

${ }^{13}$ SHEPHERD, M. In The Training of Psychiatrists (Ed Russell and Walton). British Journal of Psychiatry Special Publication No 5.1970 p 90.

14 WALton, H. J., 'Research in psychiatric education'. Psychiatric Quarterly. 1972, 44, 532-42.
Lidz-wholly unproved though those theories remain. The NSF's modest programme of publications has been of such high quality that they are already widely quoted, and the latest two are well up to standard.

One of the Fellowship's initiatives was to provide a professional advisor/coordinator for relatives of schizophrenics in one Health Area (Surrey) over a two-year period. Acting directly for families, she was to identify gaps in the services provided and try to improve communications between all their staffs and the users. Mrs Priestley has written an impressive account of her experience, not least because she had to start by defining the functions of a new kind of professional worker. Focussing on needs that are not being met, she describes the local organization of the NHS 
psychiatric services, of the Social Services, of employment facilities and of the voluntary sector. A dog's breakfast of NHS tiers, hospital catchment areas, social service districts and other administrative boundaries emerges, though Surrey-with its huge concentration of mental hospital beds-suffers more than the average from this problem.

Community psychiatric nursing is something, like the former British Empire, which we seem to have acquired in a fit of absent-mindedness, and its model of mental illness is generally quite different from that of social work, yet Mrs Priestley points out that, this divergence is rarely if ever discussed openly. She found that relatives of schizophrenics were very unlikely to take their problems to Social Services, which they did not see as being in a position to help them. On the other hand, one CPN was covering a district of 138,000 people single-handed; so it is evident that this alternative is not always available. However, this report is not simply a demand for more; it emphasizes that 'without radical rethinking and redeployment of services it is unlikely that increased resources... will have any (great) effect on the situation.' It also draws attention to that unavoidable double-bind of social policy that 'provision escalates demand, uncovers need, raises expectations, and changes the definition of an acceptable state of "health" '.

\section{Correspondence}

\section{Computerization and Confidentiality \\ DeAR SIR,}

This subject is the cause of very widespread concern at present, but some local experience may be worth recording.

The East Sussex Social Services Department, like many another, has bought itself an expensive computer which it calls a 'client data base'. Some months ago social workers working in hospitals were told that they, like social workers working elsewhere, were to provide the machine with identifying information about all hospital patients they had dealings with, and it was proposed that they would be helped in their work if visual display units were installed in hospital social work departments. Many of the social workers objected strongly on the grounds that to provide such information as a matter of routine, and without the patients' permission would be a breach of confidentiality. They agreed, as we do, that in an individual case where a social provision is to be made the Department needs information, but that the patient should be told that it is to be given. After some argument, the hospital social workers were given an ultimatum, and at that point the doctors heard about it and found a situation with ramifications of which they were unaware.
'Home Sweet Nothing' is a succinct and cogent discussion paper, with the immediate aim of stimulating debate on the practical possibilities of setting up a Campus Community for chronically handicapped schizophrenics. It states that the dilemma of how to assess the right environment for rehabilitation or resettlement can only be answered within a continuum of care, under a single management. Since the 1975 White Paper there has been little development of hostels, which in any case are only a partial answer. As a complete purpose-built community would need more capital than is likely to be available, growth is suggested from a nucleus of existing buildings, which would be fairly near each other. Using joint funding, it could be a cooperative venture between health and social services, one of them being responsible for management. The most doubtful and expensive aspect of the proposal is that this community should have its own staff, since the cost of anything more than a handful of these would almost certainly sink it without trace. Now is not a very promising time for new initiatives, but, as the NSF point out, "the best practice is already tending in the direction of an integrated network.' If a real humane alternative to the long-stay mental hospital is to be found, almost certainly this is it.

Hugh Freeman

The Social Services Department emphasizes that computerization of data about their clients helps to avoid unnecessary staff effort, particularly in dealing with different members of one family, that it helps in predicting possible episodes of non-accidental injury to children (NAIC) and improves the efficiency of social work management. They take the view that the system they have set up is a secure one so that transfer to it of information about hospital patients would not breach confidentiality, and that the information to be computerized does not include sensitive material such as diagnoses. The doctors from all specialties have unanimously opposed these arguments, saying that information derived from work in hospital should stay within the established confidential system for which they are responsible, and that if information were allowed to pass routinely outside that system they could have no control over it, now or in the future. Having stated that as a matter of principle, they see no reason to be concerned with the security of the system, but they point out that many of their patients are unwilling for it to be known even that they have been in hospital or attended a clinic (often true for psychiatric patients, presumably more so for VD clinics, or for some who have illegitimate babies), that computers easily 